Jurnal Kesehatan Terpadu (Integrated Health Journal)

Vol. 11 No. 2, November 2020 (52-57)

ISSN 1978-7766 (Print) and ISSN 2597-9566 (Online)

Journal homepage: https://www.jurnalpoltekkesmaluku.com/index.php/JKT

\title{
Riwayat Komplikasi Maternal terhadap Insiden Kelahiran Prematur di RSUD Dr. H. Chadan Boesoirie Ternate
}

The History of Maternal Complication and the Incidence of Premature Birth at Dr. H.Chasan Boesoirie Hospital

\author{
Siska Nawang Ayunda Maqfiro ${ }^{1}$, Irmasanti Fajrin ${ }^{1}$ \\ ${ }^{1}$ Jurusan Kebidanan Poltekkes Kemenkes Ternate, Jalan Cempaka, Tanah Tinggi Barat, Kota Ternate \\ Selatan, Maluku Utara \\ E-mail Korespondensi: siskanawang303@gmail.com
}

\begin{abstract}
Premature birth is one of the most important factors in neonatal morbidity and mortality. Based on the survey shows an increase in the incidence of premature birth at dr. H. Chasan Boesoirie hospital in 2015-2017. The purpose of this study was to determine the relationship between the history of maternal complication and the incidence of premature birth at dr. H. Chasan Boesoirie hospital used an analytic correlation research design with a cross-sectional approach. The population is all multiparity and grand multiparity at dr. H. Chasan Boesoirie hospital on January-December 2018, the sampling technique used simple random sampling, with the total sample are 196 respondents. The results show that $66,3 \%$ do not have the history of maternal complication and $85,7 \%$ do not have an incidence of premature birth. Then, that were analyzed using Spearman-rank. The results show that p-value is 0,001 (pvalue $<\alpha$ ). The conclusion that there is a relationship between the history of maternal complication and the incidence of premature birth at dr. H. Chasan Boesoirie hospital. So, it is necessary to provide information and education to pregnant women in order to plan their pregnancy well and build a referral system with primary care facilities.
\end{abstract}

Keywords: Birth, maternal complication, premature

\section{ABSTRAK}

Kelahiran prematur merupakan salah satu faktor terpenting dalam morbiditas dan mortalitas neonatal. Berdasarkan hasil survey pendahuluan, diketahui adanya peningkatan kejadian kelahiran prematur di RSUD dr. H. Chasan Boesoirie Ternate pada tahun 2015-2017. Riwayat komplikasi maternal memiliki risiko terjadi persalinan preterm. Wanita dikatakan mempunyai riwayat komplikasi maternal jika pernah mengalami keguguran atau persalinan preterm atau kematian janin dalam kandungan pada kehamilan sebelumnya. Tujuan penelitian ini adalah mengetahui hubungan antara riwayat komplikasi maternal dan insiden kelahiran prematur di RSUD dr. H. Chasan Boesoirie Ternate menggunakan desain penelitian analitik korelasional dengan pendekatan cross-sectional. Populasi penelitian adalah semua ibu bersalin multipara dan grandemultipara pada bulan Januari-Desember 2018, teknik pengambilan sampel menggunakan simple random sampling, jumlah sampel 196 responden. Hasil rekapitulasi data menunjukkan $66,3 \%$ tidak mempunyai riwayat komplikasi maternal dan 85,7\% tidak terjadi kelahiran prematur. Selanjutnya data dianalisis menggunakan uji statistik Spearman-rank. Hasil penelitian menunjukkan $p$-value $=0,001(p$-value $<\alpha)$. Kesimpulan dari penelitian ini adalah ada hubungan antara riwayat komplikasi maternal dengan insiden kelahiran prematur di RSUD dr. H. Chasan Boesoirie Ternate. Sehingga, perlu memberikan informasi dan edukasi kepada ibu hamil agar merencanakan kehamilannya dengan baik serta membangun sistem rujukan dengan fasilitas pelayanan primer.

Kata kunci: Kelahiran, komplikasi maternal, prematur 


\section{PENDAHULUAN}

Persalinan prematur menjadi salah satu faktor terpenting dalam morbiditas dan mortalitas neonatal yang mempengaruhi sekitar 14,9 juta bayi di dunia ${ }^{(1)}$. Sekitar $70 \%$ kematian perinatal disebabkan oleh berat bayi baru lahir kurang dari 2500 gram, yang sebagian besar dilahirkan prematur ${ }^{(2)}$. Insiden kelahiran prematur di negara berkembang masih tinggi. Di Afrika dan Asia Selatan, lebih dari 60\% kelahiran prematur terjadi. Indonesia berada di posisi kelima dari 10 negara yang memiliki jumlah kelahiran prematur terbesar, yaitu 675.700 kelahiran $^{(3)}$. Profil Kesehatan Maluku tahun 2015 menyebutkan bahwa persentase kelahiran prematur di Provinsi Maluku Utara berada di urutan kelima dari seluruh Kabupaten/Kota di Kepulauan Maluku yang merupakan salah satu faktor penyebab tingginya angka kematian bayi ${ }^{(4)}$.

Angka Kematian Bayi di Maluku Utara tergolong tinggi. Pada tahun 2018 di Kabupaten Halmahera Utara dilaporkan 99 kasus, Kepulauan Sula 42 kasus, dan Tidore Kepulauan dengan 38 kasus. Selain wilayah tersebut, yang perlu mendapatkan perhatian lebih adalah Kota Ternate, yang merupakan satu-satunya wilayah di Provinsi Maluku Utara dengan infrastruktur dan pelayanan kesehatan yang memadai. Selama delapan tahun sejak 2012, kota yang mendapatkan sebutan Bahari Berkesan ini melaporkan 124 kasus kematian bayi, hal ini tergolong cukup tinggi karena Kota Ternate memiliki luas wilayah tidak lebih dari $50 \mathrm{~km}^{2}$ yang hanya memiliki sekitar tiga ratus ribu penduduk ${ }^{(5)}$.

Berdasarkan hasil studi pendahuluan di Ruang Rekam Medis RSUD Dr. H. Chasan Boesoirie Ternate diperoleh data kelahiran prematur pada tahun 2015 sebanyak 14 kejadian dari 1431 persalinan $(0,98 \%)$, tahun 2016 sebanyak 36 kejadian dari 1662 persalinan $(2,17 \%)$, dan tahun 2017 sebanyak 39 kejadian dari 1330 persalinan (2,93\%). Hal ini menunjukkan bahwa telah terjadi peningkatan insiden kelahiran prematur di RSUD dr. H. Chasan Boesoirie Ternate pada 2015-2017.

Persalinan prematur adalah persalinan yang dimulai kapan saja setelah awal 20 hingga 36 minggu kehamilan ${ }^{(6)}$. Kematian perinatal akibat kelahiran prematur umumnya disebabkan karena termoregulasi, sistem pernapasan, organ pencernaan, hati, dan ginjal yang belum matur serta perdarahan pada otak, sehingga dapat menjadi infeksi dan komplikasi ${ }^{(7)}$.

Penelitian yang dilakukan oleh Aulia Amini menyatakan bahwa ada hubungan antara riwayat abortus dengan persalinan prematur pada ibu bersalin spontan di Rumah Sakit PKU Muhammadiyah Yogyakarta pada 2010-2012, tetapi secara statistik tidak bermakna ${ }^{(8)}$. Hal ini sejalan dengan penelitian yang dilakukan oleh Mustary yang juga menyatakan bahwa riwayat aborsi merupakan faktor risiko terjadinya kelahiran prematur ${ }^{(9)}$.

Penelitian oleh ${ }^{(8)}$ tidak ada hubungan antara riwayat persalinan preterm dan prematur pada ibu bersalin spontan di Rumah Sakit PKU Muhammadiyah Yogyakarta pada tahun 2010-2012, sedangkan penelitian yang dilakukan oleh Niswah memiliki hubungan yang bermakna antara riwayat persalinan prematur dengan kejadian persalinan preterm berikutnya $^{(10)}$.

Berdasarkan uraian tersebut, bidan mempunyai peran penting dalam mengurangi insiden kelahiran prematur dengan melakukan deteksi secara dini saat kehamilan. Sehingga, peneliti tertarik untuk melakukan penelitian tentang "Riwayat komplikasi maternal terhadap insiden kelahiran prematur di RSUD dr. Chasan Boesoirie Ternate".

\section{METODE PENELITIAN}

Penelitian ini menggunakan pendekatan penelitian kuantitatif dan termasuk dalam penelitian analitik korelasional. Berdasarkan waktu pengumpulan data termasuk jenis pengumpulan data cross sectional dan berdasarkan cara pengumpulan data termasuk jenis survei.

Populasi dalam penelitian ini adalah semua ibu bersalin multipara dan grandemultipara di RSUD dr. H. Chasan Boesoirie Ternate pada bulan Januari hingga 
Desember 2018, sebanyak 384 orang. Sampel dihitung berdasarkan rumus Slovin diperoleh 196 orang dan diambil menggunakan teknik simple random sampling. Instrumen yang digunakan adalah lembar pengumpul data. Bahan dalam penelitian ini berupa buku sensus pasien yang ada di Ruang Rekam Medis RSUD dr. H.Chasan Boesoirie Ternate.

Definisi operasional riwayat komplikasi (variabel bebas) maternal merupakan wanita yang pernah mengalami keguguran atau persalinan prematur atau kematian janin dalam kandungan/Intrauterin Fetal Death (IUFD) pada kehamilan sebelumnya, skala data ordinal, dengan kriteria ada riwayat komplikasi maternal dan tidak ada riwayat komplikasi maternal.

Definisi operasional kelahiran prematur (variabel terikat) yaitu kelahiran atau pengeluaran hasil konsepsi pada usia kehamilan 20-36 minggu dan berat lahir bayi adalah 1000 hingga 2500 gram, skala data ordinal, dengan kriteria terjadi kelahiran prematur dan tidak terjadi kelahiran prematur. Analisa data penelitian ini menggunakan uji statistik Spearman rank.

Penelitian ini telah memperoleh persetujuan etik (Ethical approval) dari Unit Komisi Etik Penelitian Kesehatan Poltekkes Kemenkes Ternate dengan nomor LB.02.04/2.3/125/2019

\section{HASIL}

Tabel 1. Data Karakteristik Demografi dan Klinik untuk Subjek Penelitian

\begin{tabular}{ll}
\hline \multicolumn{1}{c}{ Karakteristik } & \multicolumn{1}{c}{$\mathbf{N}(\%)$} \\
\hline Umur: & \\
Berisiko (<20 dan $>35$ tahun) & $59(30,1)$ \\
Tidak berisiko (20-35 tahun) & $137(69,9)$ \\
\hline Pendidikan: & \\
Pendidikan dasar & $91(46,4)$ \\
Pendidikan menengah & $84(42,9)$ \\
Pendidikan tinggi & $21(10,7)$ \\
\hline Pekerjaan: & \\
Bekerja & $58(29,6)$ \\
Tidak bekerja & $138(70,4)$ \\
\hline Paritas: & $186(94,9)$ \\
Multipara & $10(5,1)$ \\
Grandemultipara & \\
\hline Riwayat komplikasi maternal: & $66(14,3)$ \\
Ada & $130(66,3)$ \\
Tidak ada & $28(14,3)$ \\
\hline Insiden kelahiran prematur: & $168(85,7)$ \\
Ada & $196(100)$ \\
\hline \multicolumn{2}{c}{$\quad$ Tidak ada }
\end{tabular}

Berdasarkan tabel 1 dapat diketahui bahwa data karakteristik demografi dan klinik responden sebagian besar $(69,9 \%)$ memiliki usia tidak berisiko (20-35 tahun), sebagian besar $(46,4 \%)$ berpendidikan dasar (SD-SMP), sebagian besar $(70,4 \%)$ tidak bekerja, hampi seluruhnya $(94,9 \%)$ multipara, sebagian besar $(66,3 \%)$ tidak memiliki riwayat komplikasi maternal, dan sebagian besar $(85,7 \%)$ tidak terjadi kelahiran prematur. 
Tabel 2. Tabulasi Silang Riwayat Komplikasi Maternal dengan Insiden Kelahiran Prematur di RSUD dr. Chasan Boesoirie Ternate

\begin{tabular}{lccc}
\hline \multirow{2}{*}{$\begin{array}{c}\text { Riwayat komplikasi } \\
\text { maternal }\end{array}$} & \multicolumn{2}{c}{ Insiden kelahiran prematur } & \\
\cline { 2 - 3 } & $\begin{array}{c}\text { Ada insiden } \\
\text { prematur } \\
\mathbf{n}(\boldsymbol{\%})\end{array}$ & $\begin{array}{c}\text { Tidak ada insiden } \\
\text { prematur } \\
\mathbf{n}(\boldsymbol{\%})\end{array}$ & $\begin{array}{c}\text { Total } \\
\mathbf{n}(\boldsymbol{\%})\end{array}$ \\
\hline Ada riwayat & $17(8,7)$ & $49(25)$ & $66(33,7)$ \\
Tidak ada riwayat & $11(5,6)$ & $119(60,7)$ & $130(66,3)$ \\
\hline Total & $28(14,3)$ & $168(85,7)$ & $196(100)$ \\
\hline$p$ value $=0,0001$ & $\alpha=0,05$ & $\mathrm{r}=0,234$ & \\
\hline
\end{tabular}

Berdasarkan tabel 2 dapat diketahui bahwa sebagian besar dari responden $(60,7 \%)$ tidak memiliki riwayat komplikasi maternal dan tidak terjadi kelahiran prematur. Berdasarkan uji statistik diketahui $p$-value $=0,001(p$-value $<\alpha)$, hal ini menunjukkan $\mathrm{H}_{1}$ diterima dan $\mathrm{H}_{0}$ ditolak yang berarti ada hubungan antara riwayat komplikasi maternal dengan insiden elahiran prematur di RSUD dr. H. Chasan Boesoirie Ternate. Berdasarkan nilai koefisien korelasi $(r)=0,234$ maka dapat diketahui bahwa hubungan antara riwayat komplikasi maternal dengan kejadian kelahiran prematur dalam kategori rendah dan memiliki arah hubungan positif yang artinya semakin tinggi riwayat komplikasi maternal maka semakin tinggi pula insiden kelahiran prematur.

\section{BAHASAN}

Riwayat kehamilan sebelumnya akan menentukan kondisi dan kualitas kehamilan berikutnya. Jika terdapat riwayat kelahiran prematur, keguguran, atau kematian janin pada kehamilan sebelumnya merupakan faktor risiko persalinan prematur pada kehamilan berikutnya ${ }^{(11)}$. Hal ini sesuai dengan tabulasi data tabel 1, bahwa sebagian besar responden $(60,7 \%)$ tidak memiliki riwayat komplikasi maternal dan tidak terjadi insiden kelahiran prematur. Berdasarkan uji statistik menunjukkan bahwa $p$-value $=0,001$ ( $p$-value $<\alpha)$, berarti ada hubungan antara riwayat komplikasi maternal dengan insiden kelahiran prematur di RSUD dr. H. Chasan Boesoirie Ternate. Berdasarkan nilai koefisien korelasi (r) $=0,234$, maka dapat diketahui bahwa hubungan antara riwayat komplikasi maternal dengan insiden kelahiran prematur berada dalam kategori rendah dan memiliki arah hubungan positif, artinya semakin tinggi riwayat komplikasi maternal, semakin tinggi insiden kelahiran prematur. Dengan demikian, dapat diartikan bahwa riwayat komplikasi maternal berkorelasi dengan kemungkinan kelahiran prematur berikutnya.

Riwayat abortus, persalinan prematur dan Intrauterin Fetal Death/kematian janin dalam rahim dapat merusak dinding uterus. Karena uterus merupakan tempat implantasi plasenta, salah satu fungsi plasenta adalah tempat pembuatan hormon (khususnya chorionic gonadotropin, chorionic somato-mammotropins, esterogen dan progesteron) dan jika plasenta tidak berfungsi dengan baik, maka produksi hormon pada kehamilan berikutnya akan terganggu. Jika kadar hormon terganggu, terutama hormon progesteron, maka kontraksi dalam rahim akan mudah timbul pada kehamilan berikutnya ${ }^{(12)}$. Selain itu, abortus juga memungkinkan dilakukannya prosedur ginekologis. Prosedur ginekologis dapat merusak leher rahim, sehingga leher rahim tidak mampu menopang berat bayi yang sedang tumbuh $^{(13)}$. Akibatnya, leher rahim yang tidak kompeten akan berdilatasi tanpa disertai nyeri, mules selama trimester kedua kehamilan atau awal trimester ketiga diikuti dengan penonjolan dan robekan pada selaput ketuban dan pelepasan hasil konsepsi ${ }^{(14)}$. Keluarnya hasil konsepsi pada trimester kedua atau awal trimester ketiga menunjukkan bahwa hasil konsepsi keluar sebelum usia kehamilan cukup bulan atau sering disebut persalinan prematur.

Riwayat persalinan prematur dan abortus juga merupakan faktor yang sangat erat 
dengan persalinan prematur berikutnya. Ibu yang pernah mengalami persalinan prematur sebelumnya akan berisiko 3,65 kali terjadi persalinan prematur kembali ${ }^{(10)}$.

Berbagai penelitian telah dilakukan untuk mencari faktor-faktor risiko terjadinya persalinan prematur, tetapi adanya faktor-faktor risiko tersebut tidak selalu menyebabkan terjadinya persalinan prematur, dan hasil penelitian sebelumnya yang telah dilakukan masih menimbulkan inkonsistensi atau perbedaan dalam hasil penelitian. Penelitian yang dilakukan oleh Agustiana dengan hasil bahwa tidak ada hubungan yang signifikan antara umur, pemeriksaan antenatal care, pendidikan dan riwayat aborsi dengan kelahiran prematur ${ }^{(12)}$. Penelitian ini tidak sesuai dengan penelitian yang dilakukan oleh Rerung yang menunjukkan ada hubungan antara usia, pekerjaan, paritas, anemia dan antenatal care dengan persalinan prematur $^{(15)}$. Penelitian yang dilakukan oleh Rahmawati menunjukkan ada hubungan antara anemia, jarak kehamilan, paritas dengan persalinan prematur dan tidak ada hubungan antara usia dengan persalinan prematur ${ }^{(16)}$. Sedangkan penelitian oleh Paembonan menunjukkan bahwa ada hubungan antara riwayat kelahiran prematur, pleeklamsi dengan persalinan prematur dan tidak ada hubungan antara paritas, jarak kehamilan, anemia dan riwayat abortus dengan persalinan prematur ${ }^{(17)}$. Terdapat inkonsisten atau perbedaan hasil penelitian sebelumnya seperti variabel, antenatal care, riwayat aborsi, anemia, dan jarak kehamilan.

Riwayat persalinan prematur merupakan faktor yang sangat erat dengan kelahiran prematur berikutnya. Risiko kelahiran prematur naik 3 kali lipat dibandingkan dengan wanita yang bayi pertamanya mencapai tahap matur. Persentase kemungkinan kelahiran prematur akan berulang pada ibu hamil yang pernah mengalami 1 kali persalinan prematur sebesar $15 \%$, sedangkan pada ibu yang mengalami persalinan prematur 2 kali memiliki risiko $32 \%$ mengalami persalinan prematur ${ }^{(18)}$. Ibu dengan riwayat abortus berisiko mengalami kelahiran prematur 5,29 kali dibandingkan dengan ibu yang tidak memiliki riwayat abortus ${ }^{(10)}$.

Dalam penelitian Agustiana menyebutkan bahwa ibu yang memiliki riwayat abortus memiliki kemungkinan 1,1 kali lebih besar mengalami kelahiran prematur dibandingkan dengan ibu yang tidak memiliki riwayat abortus tetapi secara statistik tidak signifikan ${ }^{(12)}$. Sebaliknya, hasil penelitian yang dilakukan di Rumah Sakit Budi Kemuliaan Jakarta, bahwa ibu yang memiliki riwayat abortus secara statistik tidak bermakna / tidak ada hubungan antara riwayat abortus dengan persalinan prematur ${ }^{(19)}$.

Persalinan prematur merupakan kelainan proses yang multifaktorial. Kombinasi faktor ibu, demografi, psikososial dan genetika dapat berpengaruh terhadap kelahiran prematur. Penyebab kelahiran prematur adalah iatrogenesis (20\%), sepsis (30\%), ketuban pecah sebelum kehamilan aterm (20-25\%), dan kelahiran prematur secara spontan (20$25 \%)^{(20)}$. Di Amerika Serikat, faktor risiko persalinan preterm dibagi menurut penelitian berbasis bukti, yaitu jarak persalinan kurang dari 18 bulan dan lebih dari 60 bulan, terjadinya persalinan prematur pada kehamilan sebelumnya, suku/ras, umur ibu kurang dari 20 tahun dan melebihi 40 tahun, status gizi ibu, kondisi stres, tubuh terjangkit infeksi, tingkat sosial ekonomi yang rendah, perokok aktif maupun pasif atau pengkonsumsi alkohol atau pengguna kokain, pengaruh plasenta, dan gemeli $^{(21)}$.

Hasil analisis peneliti menunjukkan bahwa riwayat komplikasi maternal yang buruk sangat berpengaruh terhadap persalinan prematur, sehingga pengakajian riwayat komplikasi maternal sebelumnya perlu dilakukan secara akurat untuk membantu mendeteksi dini jika ada hal-hal yang mengharuskan ibu dirujuk untuk mendapatkan penanganann lebih lanjut. Dengan menyadari riwayat kehamilan sebelumnya akan membantu bidan dalam merencanakan asuhan antenatal individual dengan tepat.

\section{SIMPULAN}

Ada hubungan antara riwayat komplikasi maternal dengan insiden kelahiran prematur di RSUD dr. H. Chasan Boesoirie Ternate dengan kekuatan hubungan rendah dan arah hubungan positif. 


\section{SARAN}

Perlunya memberikan informasi dan edukasi kepada ibu hamil agar merencanakan kehamilannya dengan baik serta membangun sistem rujukan dengan fasilitas pelayanan primer seperti Puskesmas, Rumah Bersalin, Bidan Praktek Swasta, maupun Praktek Dokter Spesialis yang ada di sekitar wilayah RSUD dr. H. Chasan Boesoirie Ternate, agar rujukan kegawatdaruratan maternal neonatal dapat lebih efetif dan tepat waktu.

\section{RUJUKAN}

1. Boghossian NS, McDonald SA, Bell EF, Carlo WA, Brumbaugh JE, Stoll BJ, et al. Association of antenatal corticosteroids with mortality, morbidity, and neurodevelopmental outcomes in extremely preterm multiple gestation infants. JAMA Pediatr. 2016;

2. Ke L, Lin W, Liu Y, Ou W, Lin Z. Association of induced abortion with preterm birth risk in first-Time mothers. Sci Rep. 2018;

3. CNN Indonesia. Sadari Risiko Kesehatan dari Kelahiran Prematur [Internet]. 2018. Available from: https://www.cnnindonesia.com/gaya-hidup/20181116114315-255-347072/sadari-risikokesehatan-dari-kelahiran-prematur

4. Kemenkes RI. Profil Kesehatan Provinsi Maluku tahun 2015. 2015.

5. Burgianto B. Penyebab Tingginya Angka Kematian Bayi Di Maluku Utara [Internet]. Maluku Utara; 2019. Available from: https://kieraha.com/penyebab-tingginya-angka-kematian-bayi-dimaluku-utara/

6. Varney, Halen;Kriebs, Jan.M;Gegor C. Varney. Buku Ajar Asuhan Kebidanan. Jakarta : EGC ; 2010. Jakarta: EGC. 2010.

7. Manuaba. Ilmu Kebidanan, Penyakit Kandungan, dan KB. Ilmu Kebidanan, Penyakit, Kandungan, dan KB. 2012.

8. Amini A. Analisis Faktor-faktor Yang Berhubungan Dengan Persalinan Prematur Pada Ibu Bersalin Spontan di Rumah sakit PKU Muhammadiyah Kota Yogyakarta tahun 2010-2012. Univ Aisyiyah, Yogyakarta. 2012;53(9):1689-99.

9. Mustary M. Analisis Faktor Risiko Kejadian Kelahiran Prematur di RSIA Pertiwi dan RSIA Siti Fatimah Makassar Tahun 2011. Universitas Hasanuddin Makassar; 2011.

10. Niswah F. Faktor yang Mempengaruhi Persalinan Prematur di RSUD Tegurejo Semarang. [Internet]. Universitas Negeri Semarang; 2016. Available from: http://library.unnes.niswah

11. Jefferson R. Pengelolaan Persalinan Prematur. 2004.

12. Agustiana T. Faktor-faktor yang berhubungan dengan persalinan prematur di Indonesia Tahun 2010 (Analisis Data Riskesdas 2010). Universitas Indonesia; 2012.

13. Wheeler L. Buku Saku Asuhan Pranatal dan Pascapartum. Jakarta: EGC; 2004.

14. Wiknjosastro H. Ilmu Bedah Kebidanan. Jakarta: Bina Pustaka Sarwono Prawirohardjo; 2010.

15. Rerung NM. Faktor Risiko Kejadian Persalinan Prematur Di Rumah Sakit Daya Makassar Tahun 2011. 2014;4:90-7.

16. Rahmawati D. Faktor-faktor yang mempengaruhi terjadinya persalinan preterm di RSUD dr. moewardi surakarta. Fak Ilmu Kesehat Univ Muhammadiyah Surakarta. 2013;

17. Paembonan N, Ansar J, Arsyad DS. Faktor Risiko Kejadian Kelahiran Prematur di Rumah Sakit Ibu dan Anak Siti Fatimah Kota Makassar. 2013;1-10.

18. Cunningham, Leveno, Bloom, Hauth, Rouse, Spong. Obstetri Williams. In: Obstetri Wiliams. 2014.

19. Irmawati. Pengaruh Anemia Ibu Hamil Dengan Terjadinya Persalinan Prematur di Rumah Sakit Ibu dan Anak Budi Kemuliaan Jakarta. Universitas Indonesia; 2010.

20. Norwitz ER, Schorge JO. At a Glance Obstetri Dan Ginekologi. a Glance Obstet dan Ginekol Ed Kedua. 2006;

21. Krisnadi S, Effendi J, Pribadi A, editors. Prematuritas. Bandung: Refika Aditama Original; 2013. 